\title{
Correspondence
}

\section{Anaesthesia and mediastinal masses}

To the Editor, In spite of a plethora of literature admonishing the hazards of general anaesthesia in symptomatic patients with anterior mediastinal masses, ${ }^{1-4}$ cases continue to be reported where a child (or adult) with a potentially curable tumour has died because of disregard of the warnings. 5,6 In the current review, ${ }^{7}$ under "Anesthetic Management," the authors discuss bringing symptomatic patients to the $\mathrm{OR}$ in the sitting position to achieve adequate ventilation. They also describe as indicated by the severity of symptoms installation of arterial lines and Swan Ganz catheters. I wonder why a symptomatic patient, whether it be from tracheo-bronchial, pulmonary arterial, or superior vena canal obstruction should be brought to the operating room for general anaesthesia at all? It is unfortunate to assume that inhalational induction of anaesthesia with spontaneous ventilation in symptomatic patients will protect against disaster. Indeed the antithesis of this is reported in the literature.

In their conclusion the authors correctly suggest: in symptomatic patients requiring a diagnosis with tissue biopsy, a local anaesthetic should be employed. To this recommendation should be added the asymptomatic patient with significant abnormalities on supine and upright flow volume loops or echo cardiography. ${ }^{4}$ It has been well documented that the inflammatory response associated even with benign tumours is eminently responsive to short course radio-therapy and a window can be left to establish a histological diagnosis if necessary once the patient's symptoms and signs have resolved.

The flow sheet recommended in the excellent review by Newman et al. ${ }^{4}$ is logical, safe, and if followed, should preclude further reporting of tragic anaesthetic disasters.

\section{Roy Greengrass MD \\ Department of Anesthesia \\ University of Manitoba \\ Winnipeg, Manitoba}

\section{REFERENCES}

1 Keon TP. Death on induction of anesthesia for cervical node biopsy. Anesthesiology 1981; 55: 471-2.

2 Bray RT, Fernandes FT. Mediastinal tumour causing airway obstruction in ancsthetized children. Anaesthesia 1982; 37: 571-5
3 Mackie AM, Watson CB. Anaesthesia and mediastinal masses. A case report and review of the literature. Anaesthesia 1984; 39: 899-903.

4 Newman $G G$, Weingarten $A E$, Abramowitz $R M$ et al. The anesthetic management of the patient with an anterior mediastinal mass. Anesthesiology 1984; 60: 144-7.

5 Levin $H$, Bursztein $S$, Heifetz $M$. Cardiac arrest in a child with an anterior mediastinal mass. Anesth Analg 1985; 64: $1129-30$

6 Northrip DR, Bohman BK, Tsueda $K$. Total airway occlusion and superior vena cava syndrome in a child with an anterior mediastinal tumor. Anesth Analg 1986; 65 : 1079-82.

7 Pullerits J, Holzman R. Anacsthesia for patients with mediastinal masses. Can J Anaesth 1989; 36: 681-8.

\section{REPLY}

Dr. Greengrass questions why a patient symptomasic from tracheobronchial, pulmonary arterial or SVC obstruction should ever be anaesthetized and asserts that it is "unfortunate to assume that inhalational induction of anaesthesia with spontaneous ventilation in symptomatic patients will protect against disaster." Our review article clearly supports the notion that an inhalational induction is no guarantee against disaster. Indeed, we referred to a number of papers that describe asymptomatic patients who developed complications during anaesthesia. ${ }^{1-3}$ There are, however, situations in clinical practice where a general anaesthetic may be the only option available after all investigations have been performed, especially in children where patient cooperation may be absent. We thank Dr. Greengrass for referring us to a clinical report by Neuman et al. ${ }^{4}$ that contains a useful algorithm for the preoperative evaluation of these perplexing patients but point out that on the flow sheet referred to, Dr. Newman himself suggests general anaesthesia should be used if local anaesthesia is impractical. The thrust of our review article is not to present a single approach to this complex problem but rather to emphasize the need for a thorough understanding of the underlying pathophysiology.

John Pullerits MD FRCPC

R. Holzman MD

\section{REFERENCES}

1 John RE, Narang VPS. A boy with an anterior mediastinal mass. Anaesthesia 1988; 43: 864-6.

2 Bray RJ, Fernandes FJ. Mediastinal tumour causing airway obstruction in anaesthetized children. Anaesthesia 1982; 37: 571-5.

3 deSoto J. Direct laryngoscopy as an aid to relieve airway obstruction in a patient with a mediastinal mass. Anesthesiology 1987; 67: 116-7. 
4 Newman $G G$, Weingarten $A E$, Abramowitz RM et al. The anesthetic management of the paticnt with an anterior mediastinal mass. Ancsthcsiology 1984; 60: 144-7.

\section{Inadequate analgesia with lumbar epidural following retroperitoneal dissection}

To the Editor:

We wish to report a problem with incomplete spread of epidural analgesia following radical retroperitoneal dissection.

Radical retroperitoneal dissection has recently been proven to be the most effective method for treating retroperitoneal malignancies, especially of testicular origin. The operative procedure involves a thoraco-abdominal exploration with en bloc removal of retroperitoneal structures up to the level of the diaphragm. Epidural analgesia has been suggested as an effective method of postoperative pain relief without compromizing pulmonary function in patients undergoing this procedure.' Many of these patients receive bleomycin therapy before surgery and may be at increased risk of developing the adult respiratory distress syndrome (ARDS) postoperatively; administration of a high $\mathrm{FlO}_{2}$ is thought to be contributory in such instances.

At our institution, we routinely employ epidural analgesia postoperatively for patients undergoing thoracoabdominal dissections. Of the 90 patients treated in this manner, satisfactory analgesia could not be achieved in nine patients. In those patients pain persisted in the upper areas of the incision despite both motor and sensory blockade in the lower abdomen and extremities and mild to moderate hypotension with each activation. Moreover, relatively large volumes of local anaesthetic solution (bupivacaine $25-30 \mathrm{ml}, 0.5$ per cent or lidocaine $15-25$ $\mathrm{ml} 1.5$ per cent solution) were used unsuccessfully in each instance, even with the patient in the Trendelenberg position. We also observed that in all nine patients the epidural catheter was placed at the $\mathrm{L}_{4}-\mathrm{L}_{5}$ interspace, and that placement of another catheter at the $L_{1}-L_{2}$ interspace with the tip directed 6 to $10 \mathrm{~cm}$ cephalad achieved satisfactory pain relief.

Anatomically, the epidural space communicates laterally with the paravertebral space through the intravertebral foramina. The paravertebral space is limited laterally and anteriorly by retroperitoneal tissue. Following radical retroperitoneal dissection, the paravertebral space communicates freely with the retroperitoneal space. ${ }^{2-6} \mathrm{We}$ suggest that epidural injection of a local anaesthetic at or below the level of the dissection results in leakage of the solution from the epidural space through the intravertebral foramina into the retroperitoneal space. Reduced retention and spread of the anaesthetic solution within the epidural space would explain the initial inadequate pain relief with the $L_{4}-L_{5}$ catheter in our nine patients. We now place epidural catheters at $\mathrm{L}_{1}-\mathrm{L}_{2}$ routinely in patients undergoing thoraco-abdominal resections, and since have had uniformly satisfactory analgesic results.

Duraiyah Thangathurai MD FFARCS

Maged Mikhail MD

David Fishmañ $M D$

University of Southern California School of Medicine

Kenneth Norris Jr Cancer Cancer Hospital and Research Institute

Los Angeles, CA.

\section{REFERENCES}

1 Bromage PR, Camporesi E, Chesinut D. Epidural narcotics for post-opcrative analgesia. Anesth Analg 1980; 59: 473-80.

2 Burn JM, Guyer PB, Langdon $L$. The spread of solutions injected into the epidural space. Br J Anaesth 1973; 45; 338-345.

3 Luyendijk $W$, van Voorthuisen $A E$. Contrast examination of the spinal epidural space. Acta Radiol 1966; 5: 1051-66.

4 Nishimura N, Kitahara T, Kusakabe T. The spread of lidocaine and 1-131 solution in the epidural space. Anaesthesiology 1959; 20: 785.

5 Husemeyer RP, White DC. Lumbar extradural injection pressures in pregnant women. $\mathrm{Br} \mathrm{J}$ Anaesth 1980; 52: 55-60.

6 Macintosh RR, Mushin WW. Observations on the epidural space. Anaesthesia 1947; 2: 100.

\section{Measurement of gastric contents}

To the Editor:

We agree with the conclusion of Taylor et al.' that blind aspiration of gastric contents gives a fair estimate of volume, even if this is always an underestimate (the same may be true of dye dilution techniques). ${ }^{2}$ One cannot determine from their data whether all of the additional volume obtained under direct vision with a gastroscope remained in the stomach following the initial blind aspiration, or represented endogenous secretions in response to the Salem sump tube and the gastroscopy 